\title{
Stromal Cell-Derived Factor-1 (Chemokine C-X-C Motif Ligand 12) and Chemokine C-X-C Motif Receptor 4 Are Required for Migration of Gonadotropin-Releasing Hormone Neurons to the Forebrain
}

\author{
Gerald A. Schwarting, ${ }^{1,2}$ Timothy R. Henion, ${ }^{1,2}$ J. David Nugent, ${ }^{1}$ Benjamin Caplan, ${ }^{1}$ and Stuart Tobet ${ }^{3}$ \\ ${ }^{1}$ Shriver Center, Waltham, Massachusetts 02452, ${ }^{2}$ Department of Cell Biology, University of Massachusetts Medical Center, Worcester, Massachusetts \\ 01655, and ${ }^{3}$ College of Veterinary Medicine and Biomedical Science, Colorado State University, Fort Collins, Colorado 80523
}

\begin{abstract}
Gonadotropin-releasing hormone (GnRH) neurons migrate from the vomeronasal organ (VNO) in the nasal compartment to the basal forebrain in mice, beginning on embryonic day 11 (E11). These neurons use vomeronasal axons as guides to migrate through the nasal mesenchyme. Most GnRH neurons then migrate along the caudal branch of the vomeronasal nerve to reach the hypothalamus. We show here that stromal cell-derived factor-1 [SDF-1, also known as chemokine C-X-C motif ligand 12 (CXCL12)] is expressed in the embryonic nasal mesenchyme from as early as E10 in an increasing rostral to caudal gradient that is most intense at the border of the nasal mesenchyme and the telencephalon. Chemokine C-X-C motif receptor 4 (CXCR4), the receptor for SDF-1, is expressed by neurons in the olfactory epithelium and VNO. Cells derived from these sensory epithelia, including migrating GnRH neurons and ensheathing glial precursors of the migrating mass (MM), also express CXCR4, suggesting that they may use SDF-1 as a chemokine. In support of this, most GnRH neurons of CXCR4 ${ }^{-/-}$mice fail to exit the VNO at E13, and comparatively few GnRH neurons reach the forebrain. There is also a significant decrease in the total number of GnRH neurons in CXCR4 ${ }^{-I-}$ mice and an increase in cell death within the VNO relative to controls. The MM is smaller in CXCR4 $4^{-1-}$ mice, suggesting that some MM cells also require SDF-1/CXCR4 function for migration and survival.
\end{abstract}

Key words: gonadotropin-releasing hormone; luteinizing hormone-releasing hormone; cell migration; migrating mass; chemokine; Kallmann's syndrome

\section{Introduction}

Chemokines have been implicated in the development of the central and peripheral nervous systems (Tran and Miller, 2003). Stromal-derived factor-1 [SDF-1, also known as chemokine $\mathrm{C}-\mathrm{X}-\mathrm{C}$ motif ligand 12 (CXCL12)] is a particularly versatile chemokine in that it can act as a chemoattractant for granule cell precursors in the developing cerebellum and the dentate gyrus of the hippocampus (Bagri et al., 2002; Lu et al., 2002; Zhu et al., 2002). It also has been shown to regulate interneuron migration in the developing cortex (Stumm et al., 2003) and to promote survival of retinal ganglion cells (Chalasani et al., 2003). Chemokine (C-X-C motif) receptor 4 (CXCR4) is the only known receptor for SDF-1, and mice that lack either SDF-1 or CXCR4 show similar developmental abnormalities (Ma et al., 1998; Zou et al., 1998). It was shown recently that dorsal root ganglia (DRG) were smaller and malformed in CXCR $4^{-1-}$ mice, indicating that SDF-

Received Jan. 5, 2006; accepted May 18, 2006.

This work was supported by National Institutes of Health Grants HD33441 and DC00953. We thank Andre Goffinet for providing the SDF- 1 and CXCR4 riboprobes.

Correspondence should be addressed to Gerald A. Schwarting, The Shriver Center/University of Massachusetts Medical Center, 200 Trapelo Road, Waltham, MA 02452. E-mail: gerald.schwarting@umassmed.edu. DOI:10.1523/JNEUROSCI.1728-06.2006

Copyright $\odot 2006$ Society for Neuroscience $\quad$ 0270-6474/06/266834-07\$15.00/0
1/CXCR4 signaling plays an important role in directing the migration of sensory neuron progenitors to DRG (Belmadani et al., 2005).

SDF-1 and CXCR4 are expressed in the developing olfactory system (Tissir et al., 2004). Early stages of olfactory development are characterized by the migration of gonadotropin-releasing hormone $(\mathrm{GnRH})$ neurons from the vomeronasal organ (VNO) to the forebrain and the migration of glial precursors, known as the migrating mass $(\mathrm{MM})$, from the olfactory epithelium $(\mathrm{OE})$ to the nerve layer of the olfactory bulb (OB) (Valverde et al., 1992). Migration of MM cells begins at embryonic day 10 (E10) and is completed by E13. GnRH neurons first emerge from the VNO at E11 and migrate over a much longer pathway to the hypothalamus until E18 (Schwanzel-Fukuda and Pfaff, 1989; Wray et al., 1989). Little is known about the mechanisms involved in the migration of either of these cell types or whether they might share any common feature that could link their migratory behaviors. We show here that loss of SDF-1/CXCR4 signaling results in the partial inhibition of the migration of MM cells and the inability of the majority of GnRH neurons to migrate from the VNO in mice. From a clinical standpoint, failure of $\mathrm{GnRH}$ neurons to migrate into the hypothalamus is the hallmark of Kallmann's syndrome (KS) (Quinton et al., 1997; Dode and Hardelin, 2004), resulting 


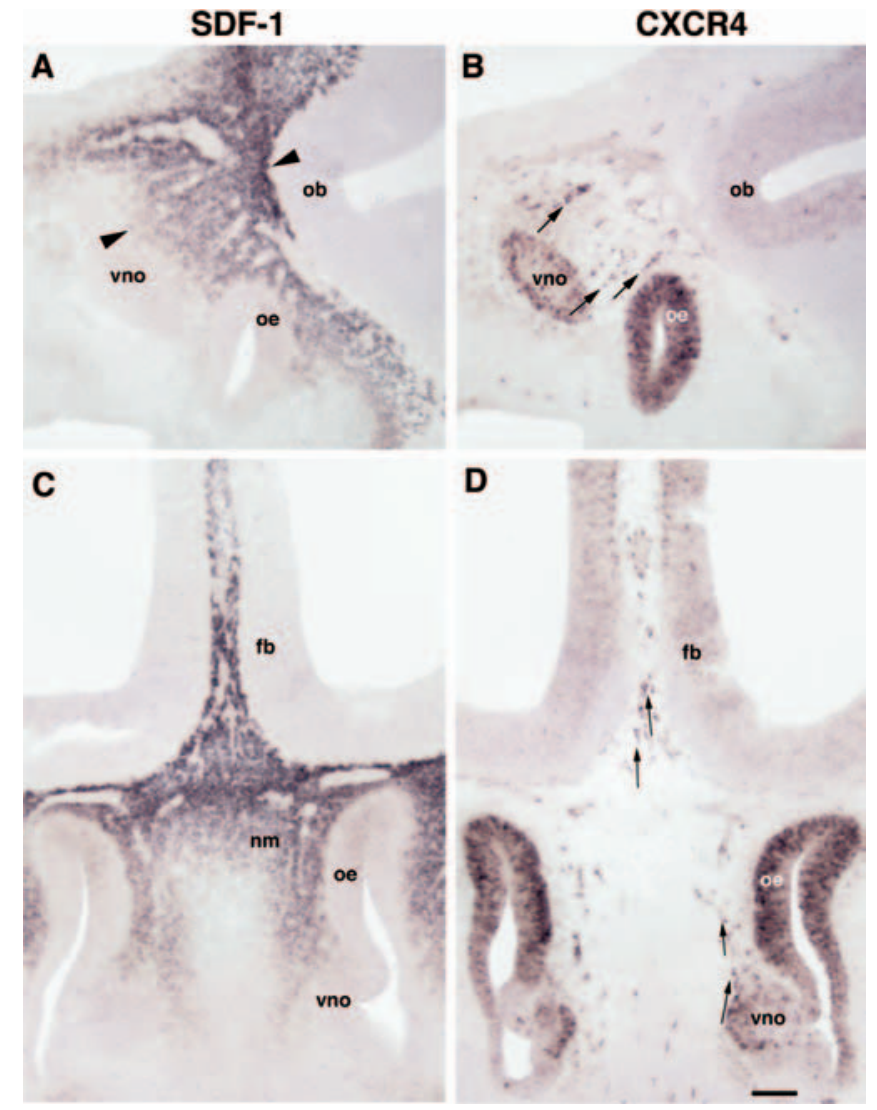

Figure 1. At E12.5 in a sagittal section (A) SDF-1 mRNA is expressed by mesenchymal cells between the $\mathrm{OE}$ and the VNO and between the arrowheads of the $\mathrm{OB}$. $\boldsymbol{B}$, In an adjacent section to $A, C X C R 4$ is expressed in the OE and the VNO and by cells dispersed in the nasal mesenchyme (arrows) between the VNO and the OB. In $\boldsymbol{A}, \boldsymbol{B}$, rostral is left, and dorsal is up. $\boldsymbol{C}$, In a horizontal section SDF-1 expression in the nasal mesenchyme $(\mathrm{nm})$ between the VNO and the forebrain (fb) is evident. $D$, Many CXCR4-positive cells are present along the pathway of migrating $\mathrm{GnRH}$ neurons in the nasal mesenchyme and into the fb (arrows). In C, D, rostral is down, and caudal is up. Scale bar, $100 \mu \mathrm{m}$.

in hypogonadotropic hypogonadism $(\mathrm{HH})$ and complete or partial loss of the sense of smell. Although genes associated with $\mathrm{X}$-linked KS have been identified, a majority of individuals with $\mathrm{HH}$ are not anosmic and do not have a mutation in the Kallmann's syndrome (KAL) gene (Oliveira et al., 2001). SDF-1/ CXCR4 provides new candidate genes/pathways for understanding the clinical and neuroendocrine phenotypes in some $\mathrm{HH}$ individuals who are not anosmic.

\section{Materials and Methods}

Animals. CXCR $4^{-1-}$ mice were obtained by breeding heterozygous CXCR4 ${ }^{+/-}$mice from The Jackson Laboratory (Bar Harbor, ME), and genotyping was performed by using a previously described PCR protocol (Ma et al., 1998). Six CXCR4 ${ }^{-1-}$ and five wild-type littermate mice were analyzed at E12 and E13. Wild-type and heterozygous mice were found to be similar (data not shown).

In situ hybridization. SDF-1 and CXCR4 probes were a generous gift from Dr. Andre Goffinet (The University of Louvain Medical School, Brussels, Belgium) (for details, see Tissir et al., 2004). The GnRH riboprobe recognized the mouse prepro-antisense sequence, as previously described (Allen et al., 2000). Digoxigenin-labeled RNA probes were generated according to the methods described in the Roche Genius kit (Indianapolis, IN). In situ hybridization was performed on 20 - $\mu$ m-thick coronal cryostat sections through the $\mathrm{OE}$ and $\mathrm{OB}$ of mice as previously described (Schwarting et al., 2004). Double-label in situ hybridizations were performed with a similar protocol, adapted for sequential detection of two alkaline phosphatase-labeled riboprobes (Jowett, 2001). Tissue sections were incubated overnight simultaneously with fluoresceinlabeled riboprobes to CXCR4 and digoxigenin-labeled riboprobes to GnRH. CXCR4 expression was localized first by using alkaline phosphatase-conjugated anti-fluorescein antibody and nitroblue tetrazolium/5-bromo-4-chloro-3-indolyl phosphate (NBT/BCIP) substrate. Residual bound alkaline phosphatase was deactivated in $0.1 \mathrm{M}$ glycine- $\mathrm{HCl}$ for $15 \mathrm{~min}$ before localization of $\mathrm{GnRH}$ expression with anti-digoxigenin alkaline phosphatase antibody visualized with iodonitrotetrazolium violet/BCIP (INT/BCIP) substrate. The yellow INT/ $\mathrm{BCIP}$ reaction product is partially soluble and marks the entire cell body of positive neurons, whereas the purple NBT/BCIP reaction product precipitates over the cytoplasm.

Histology and immunocytochemistry. For immunocytochemical experiments the heads were fixed in $4 \%$ paraformaldehyde in $0.1 \mathrm{~m}$ phosphate buffer, pH 7.4, imbedded with 30\% sucrose, and cryosectioned at $20 \mu \mathrm{m}$ thickness onto slides as previously described (Schwarting et al., 2004). Sections then were incubated in antibodies to BIII-tubulin (Sigma, St. Louis, MO) or peripherin (Chemicon, Temecula, CA) in 1\% BSA with $0.3 \%$ Triton X-100 overnight at $4^{\circ} \mathrm{C}$. For lectin labeling the sections were incubated in FITC-conjugated Lycopersicon esculentum agglutinin (LEA) lectin (Vector Laboratories, Burlingame, CA) in 1\% BSA and 0.3\% Triton X-100 overnight at $4^{\circ} \mathrm{C}$.

Cell death. Assays for apoptosis in the VNO and MM were performed by using protocols described in the DeadEnd terminal deoxynucleotidyl transferase-mediated UTP nick end labeling (TUNEL) system (Promega, Madison, WI). Visualization of TUNEL-positive cells was modified by using Vectastain $\mathrm{ABC}$ kit amplification of diaminobenzidine-nickel substrate detection (Henion et al., 2005).

\section{Results}

\section{SDF-1 and CXCR4 are expressed in the developing accessory} olfactory system

At E12.5 mice SDF-1 mRNA is expressed in the caudal half of the nasal mesenchyme (Fig. $1 A$ ). SDF-1 message is strongest bordering the telencephalon and weakest in mesenchymal cells bordering the VNO. SDF-1 is not expressed rostral or ventral to the VNO. In an adjacent section to Figure $1 A$, CXCR4 is expressed by neurons in the $\mathrm{VNO}, \mathrm{OE}$, and by many cells in positions midway between the VNO and forebrain (Fig. $1 B$, arrows). The position of these cells can be seen as gaps in the expression of SDF-1 (Fig. $1 A$ ) and coincides with the migration of GnRH neurons from the $\mathrm{VNO}$ to the forebrain at this age.

In a horizontal section through the nose and brain of an E12.5 mouse SDF-1 expression is heavy throughout the nasal mesenchyme (Fig. 1C). Spaces lacking SDF-1 expression are interspersed in the mesenchyme. In an adjacent section to Figure $1 C$, CXCR4-positive cells can be seen emerging from the VNO as in Figure $1 B$, as well as approaching the forebrain (Fig. $1 D$, arrows).

\section{SDF-1 mRNA is expressed in a rostral to caudal gradient}

In situ hybridization that used a digoxigenin-labeled SDF-1 riboprobe developed with NBT-BCIP revealed heavy expression in the mesenchyme between the VNO and the forebrain. To determine whether this expression conformed to a spatial gradient within the developing olfactory system, we measured the pixel density at several locations in the mesenchyme of E12 mice, providing a semiquantitative analysis of mRNA expression in this tissue. We took measures at five locations from the VNO to the forebrain at equally spaced locations along the rostrocaudal axis (Fig. 2A). Repeated measures analysis by region revealed that there is an increasing gradient of SDF-1 mRNA (Fig. $2 B$ ) expression that is elevated slightly above background near the VNO and increases at each subsequent caudal location. At the border of the forebrain the pixel density is more than fourfold higher than basal levels in the VNO or in the forebrain. 


\section{CXCR4 is expressed transiently by} GnRH neurons

Double-label in situ hybridization studies were performed to determine whether CXCR4 is expressed in GnRH neurons. At E13 many GnRH neurons have left the $\mathrm{VNO}$ and are migrating across the nasal septum (Fig. 3). At this age most neurons expressing GnRH (yellow) also coexpress CXCR4 (purple), although there are several examples of CXCR4-positive cells that do not contain GnRH.

At $\mathrm{E} 15>80 \%$ of $\mathrm{GnRH}$ neurons already have crossed the cribriform plate and reside in the forebrain (Fig. $4 A, B$ ). Single-label in situ hybridization studies in serial sections at E15 confirmed that there were almost no CXCR4-positive cells at the typical forebrain location of $\mathrm{GnRH}$ neurons. The few CXCR4-positive neurons in the forebrain (Fig. 4D) were marginally detectable as compared with the robust expression of CXCR4 in the OE and VNO (Fig. 4C). Double-label in situ hybridization analysis confirmed the lack of CXCR4 expression in GnRH neurons at this age (data not shown). These results suggest that CXCR4 expression in $\mathrm{GnRH}$ neurons is downregulated once they have migrated past the SDF-1 gradient into the forebrain.

\section{SDF-1 and CXCR4 are expressed in the developing main olfactory system}

The MM is a small cluster of undifferentiated precursor cells that migrate from the developing $\mathrm{OE}$ at E10 and populate axon pathways and the nerve layer of the OB by E13 in the mouse. At E10, an age when the olfactory placodes have invaginated into two large pits on the lateral surfaces of the rostral head, SDF-1 is expressed principally in the caudal mesenchyme (Fig. 5A) and is strongest in the dorsal mesenchyme that borders the telencephalon. A single row of SDF-1-negative cells (arrowhead) is positioned midway through the gradient of SDF-1-positive cells. In an adjacent section to Figure $5 A$, a single row of CXCR4-positive cells (Fig. $5 B$, arrow) is in a position that is identical to the gap in SDF-1 expression. These cells comprise the initial cells of the MM: cells that migrate from the olfactory pit (out of the plane of section) 2 full days before GnRH neurons emerge from the VNO and are in a more lateral position than medially migrating $\mathrm{GnRH}$ neurons. At E11 the SDF-1 expression pattern is unchanged, and gaps in expression are still apparent (Fig. 5C, arrowhead). Cells in the $\mathrm{MM}$ are known to divide and differentiate during the course of their migration, and at E11 CXCR4 is expressed by cells at the outer edge of the MM (Fig. 5D, arrow), but most MM cells are CXCR4-negative.

\section{GnRH neuron migration is inhibited in CXCR4 mutant mice} The role of SDF-1/CXCR4 signaling in GnRH neuronal migration was examined in CXCR4-deficient mice (Ma et al., 1998). Although most CXCR4 mutants die perinatally and have associated defects in neural crest and cerebellar development, the early stages of olfactory morphogenesis proceeded normally on a gross level. The olfactory placode of CXCR4 mutants invaginated properly from the nasal process to form medial and lateral olfacdiffered significantly from region 1.
B SDF-1 mRNA Expression

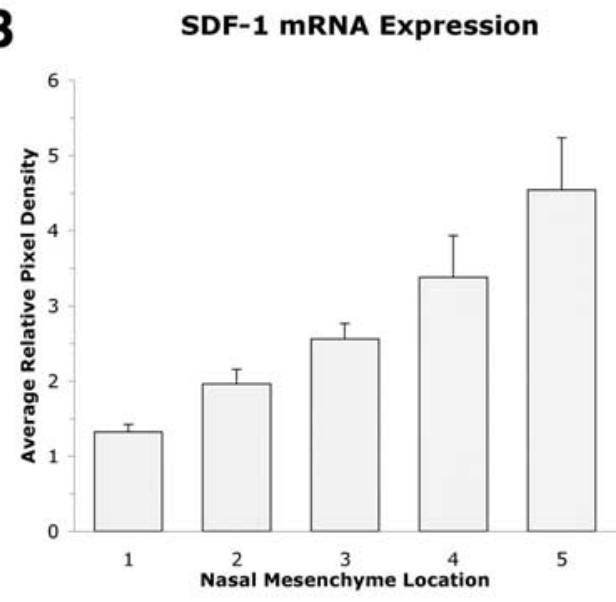

Figure 2. In situ hybridization with the digoxigenin-labeled SDF-1 riboprobe was analyzed semiquantitatively for the pixel statistically significant $\left(F_{(4,16)}=14.59 ; p<0.0001\right)$, and post hoc analysis additionally indicated that regions 3,4 , and 5 all

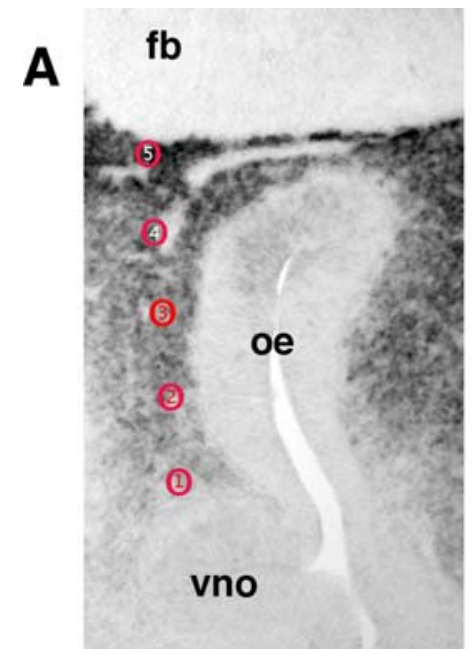




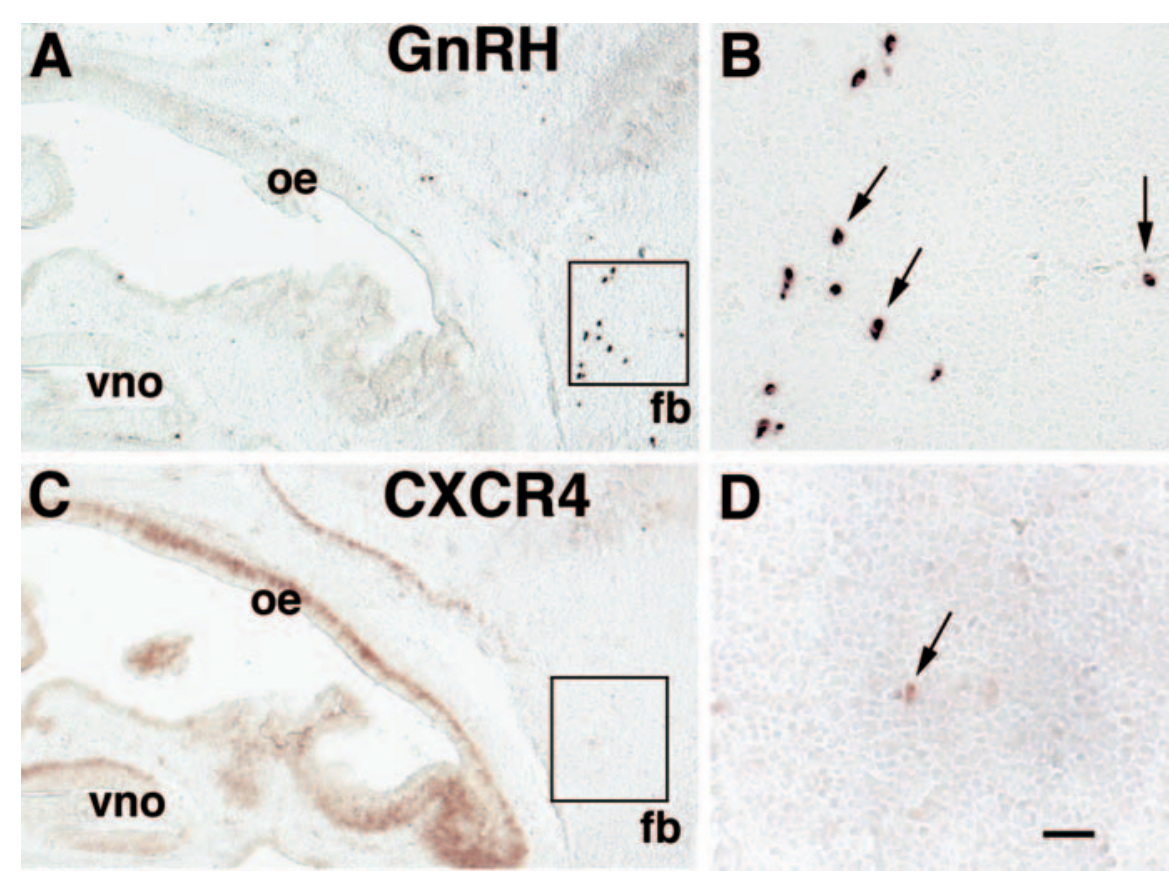

Figure 4. In sagittal sections through the nasal mesenchyme and forebrain (fb) at $\mathrm{E} 15$ a cluster of $\mathrm{GnRH}$ neurons is detected in the $\mathrm{fb}(\boldsymbol{A}$, boxed area) and is shown at high magnification in $\boldsymbol{B}$ (arrows). $\boldsymbol{C}$, In a serial section to $\boldsymbol{A}$, CXCR4 is expressed in the VN0, the $0 \mathrm{E}$, and in mitral cells of the $0 B$. $\boldsymbol{D}$, Very few neurons (arrow) in the $\mathrm{fb}$ (C, boxed area) express CXCR4 at this age. Dorsal is up, and rostral is left. Scale bars: $A, C, 200 \mu \mathrm{m} ; \boldsymbol{B}, \boldsymbol{D}, 50 \mu \mathrm{m}$.

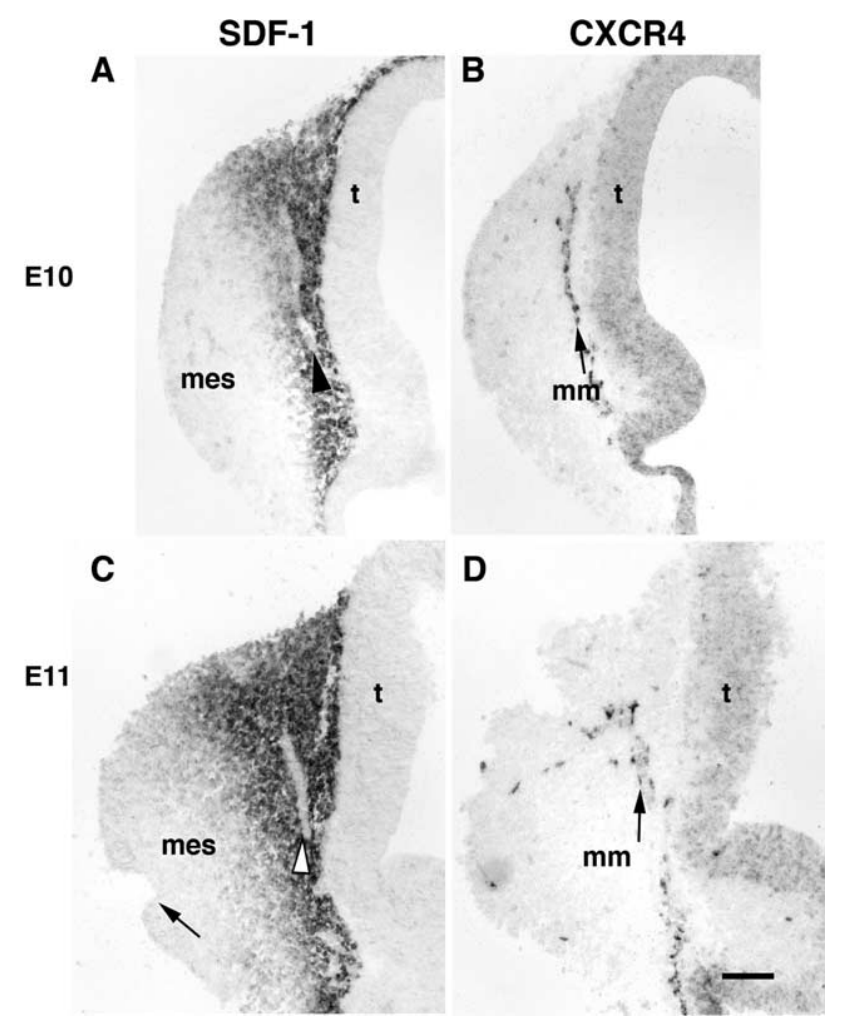

Figure 5. In sagittal sections through the nasal mesenchyme (mes) and telencephalon ( $\mathrm{t}$ ) at $\mathrm{E} 10$ $(A)$ and E11 (C) SDF-1 mRNA is expressed in mesenchymal cells in the nose in a decreasing gradient that extends from the border of the telencephalon rostrally approximately midway through the nose. AtE11 the gradient does not extend so far as the olfactory pit ( $\boldsymbol{C}$, arrow). Atboth ages there are gaps $(\boldsymbol{A}$, $\boldsymbol{C}$, arrowheads) in the SDF-1 mRNA gradient. $\boldsymbol{B}$, In an adjacent section at E10 a single row of CXCR4positive cells known as the MM (labeled as $\mathrm{mm}$; arrow) is present in the mesenchyme midway through the SDF-1 gradient ( $\boldsymbol{A}$, arrowhead). $\boldsymbol{D}$, At E11 CXCR4-positive cells (arrow) are dispersed along the borders of the MM with the mesenchyme, whereas other cells in the MM are CXCR4-negative. Rostral is left, and dorsal is up. Scale bar, $100 \mu \mathrm{m}$.
The typical position of GnRH neurons detected in CXCR4 $4^{-1-}$ mice is shown in Figure $6 B$. The vast majority of $\mathrm{GnRH}$ neurons in mutant mice remained in the VNO. Within the VNO of CXCR4 ${ }^{-1-}$ mice the GnRH neurons characteristically were restricted to the rostroventral half of the tissue (Fig. $6 B$, arrowhead). Thus not only had few GnRH neurons migrated toward the brain, but many of them were clustered at an abnormal position within the VNO. Quantitative analysis revealed that, of an average of $296 \pm 34.4 \mathrm{GnRH}$ neurons per one-half CXCR $4^{-1-}$ mouse, none was detected in the region of the cribriform plate; $<3.0 \%$ was found to be migrating through the nasal mesenchyme, and $>97.0 \%$ was detected in the VNO. These results clearly demonstrate that the majority of GnRH neurons requires CXCR4 to begin their normal migration from the VNO.

One day later at E13 the total number of GnRH neurons detected by in situ hybridization increased nearly twofold in control mice, and their distribution within the migratory pathway had changed significantly. In wild-type mice the number of GnRH neurons remaining in the VNO was reduced significantly as compared with those at E12, because most of these neurons had begun their migration across the nasal septum into the forebrain. At E13 49\% of GnRH neurons had crossed the cribriform plate of CXCR $4^{+/+}$mice (Table 1; Fig. 6C). Many GnRH neurons in the brain had turned and begun migrating toward the ventral forebrain. In CXCR4 ${ }^{-1-}$ mice at E13 (Fig. $6 D$ ) $>60 \%$ of GnRH neurons remained in the VNO, and $<3 \%$ of GnRH neurons had crossed the cribriform plate. Interestingly, of the few GnRH neurons that were found in the forebrain of CXCR4 $4^{-\prime-}$ mice, none had migrated ventrally or caudally toward the hypothalamus.

\section{The MM is abnormal in CXCR4 mutant mice}

The MM is composed mostly of undifferentiated ensheathing glial precursor cells but also contains cells with neuronal characteristics. Unlike GnRH neurons, cells within the MM proliferate and differentiate as they migrate (Valverde et al., 1992), making it a difficult population to define, quantify, or manipulate. $\beta$ IIITubulin is a neuron-specific marker that strongly labels the early olfactory axon populations that accompany MM cells during transit to the presumptive OB (De Carlos et al., 1995; Roskams et al., 1998). In addition, we found that the LEA lectin specifically interacts with olfactory cells and axons, including most elements of the MM. LEA does not label neurons in the telencephalon, allowing for a clear demarcation of the border between the MM and $\beta$ III-tubulin-positive cells in the cortical preplate. Doublelabel immunofluorescence analysis of $\beta$ III-tubulin and LEA on E12 sagittal sections of CXCR4 heterozygous and mutant mice revealed that the MM is abnormal in CXCR4 ${ }^{-1-}$ mice (Fig. 7B). It is decreased significantly in size when compared with heterozygous mice (Fig. 7A).

Although the mutant MM extends to the rostral tip of the $\mathrm{OB}$ in CXCR4 mutants similar to that of littermate controls, there is a significant decrease in the breadth of the MM as it emerges from 
the $\mathrm{OE}$ and in the number of fibers that project to the developing OB. $\beta$ IIITubulin expression in the developing $\mathrm{OB}$ and forebrain appears to be normal in the CXCR4 mutants at this age, and the OB has begun to evaginate from the forebrain normally.

Death of VNO cells in CXCR4 $4^{-1-}$ mice At E13 the total number of GnRH neurons in CXCR $4^{-1-}$ mice was approximately the same as was counted at E12. This number is $\sim 45 \%$ fewer than littermate controls at E13. TUNEL analysis was performed to examine changes in programmed cell death at E13 in the migratory route of $\mathrm{GnRH}$ neurons (Fig. $8 A, B$ ). At this age there was a large increase in the number of TUNELpositive cells in the VNO of CXCR4 $4^{-1-}$ mice as compared with controls. Interestingly, the increase in TUNEL-positive cells was highest in the ventral half of the VNO, which is the location at which GnRH neurons begin to accumulate at E12. There was no detectable increase in cell death in other regions of the $\mathrm{GnRH}$ migratory pathway.

\section{Discussion}

SDF-1 is a chemokine that plays an important role in the central and peripheral ner-

vous systems and in the immune system (Nagasawa et al., 1996; Vilz et al., 2005). It is believed that its action is mediated solely via CXCR4, a seven transmembrane G-protein-coupled receptor. We show here that SDF-1 is expressed by mesenchymal cells in the embryonic olfactory system and that CXCR4 is expressed by migrating GnRH neurons and by cells in the MM. The MM is composed mostly of precursors of ensheathing glial cells, a population of cells that is known to promote neurite extension by embryonic olfactory receptor cells (Kafitz and Greer, 1999). In CXCR4 mutant mice most GnRH cells fail to migrate from the $\mathrm{VNO}$, indicating that SDF-1/CXCR4 signaling is required for normal migration of most GnRH neurons. In addition, the MM is significantly smaller in size in CXCR $4^{-1-}$ mice, suggesting that SDF-1/CXCR4 signaling plays an important role in MM development and the subsequent functional properties of the $\mathrm{OB}$ nerve layer. SDF-1 mRNA is expressed in a steep gradient that is heaviest at the border between the telencephalon and the nasal mesenchyme. This graded expression of SDF-1 mRNA is evident at E10, when the olfactory system is in its initial stages of differentiation. As we show here, the gradient of SDF-1 mRNA expression persists at E12, when many GnRH neurons emerge from the VNO. This expression pattern and the defects observed in CXCR4 mutant mice suggest that migrating CXCR4-positive GnRH neurons may follow a positive rostral to caudal SDF-1 gradient toward the telencephalon. An analogous SDF-1 gradient mechanism has been shown recently for the migration of CXCR4-positive sensory progenitor cells to DRG (Belmadani et al., 2005).

CXCR4 is expressed by most MM cells at E10 but is lost from subsequent generations of MM cells that are produced during the course of migration. One main difference between the migration of GnRH neurons and MM cells is that GnRH cells are differen-
CXCR4 +/-
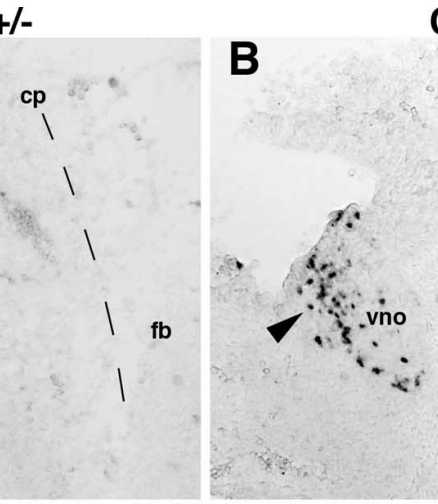

CXCR4-/-
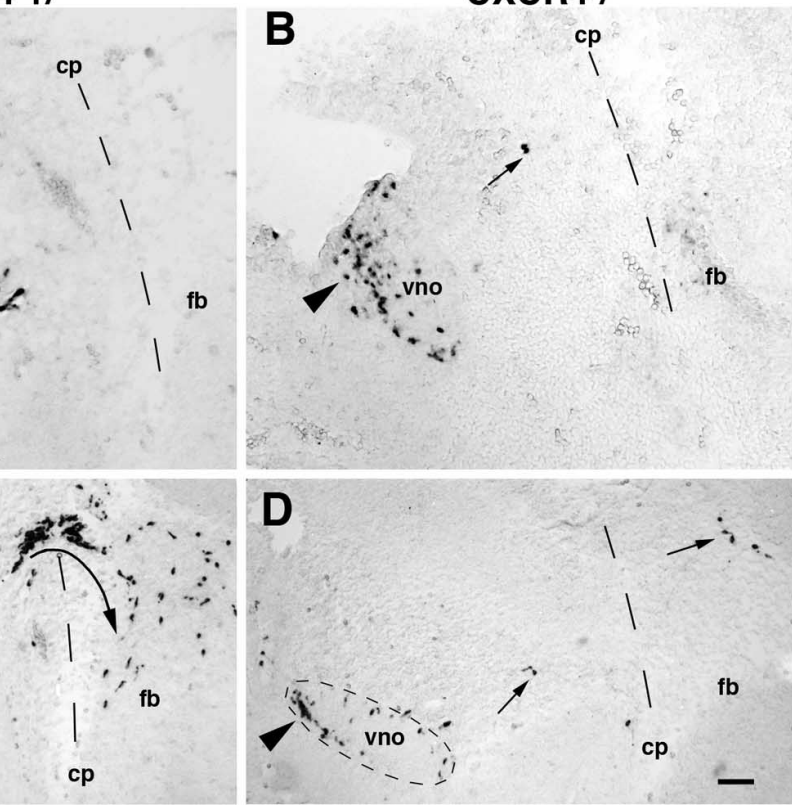

Figure 6. Most GnRH neurons fail to migrate from the VNO in CXCR4 mutant mice. $A$, At E12 in CXCR4 ${ }^{+/-}$mice GnRH neurons

urons dashed line). $\boldsymbol{B}$, In CXCR4 ${ }^{-1-}$ mice at E12 nearly all GnRH neurons are detected in the VN0, and most are clustered (arrowhead) mice (arrow). C, At E13 in CXCR4 ${ }^{+/-}$mice most GnRH neurons have migrated from the VN0, and neurons migrate across the nasal septum and cross the $\mathrm{cp}$ (arrows). Many GnRH neurons reside in the rostroventral quadrant (dashed circle; arrowhead) of the VN0. Rostral is left, and dorsal is up. Scale bar: (in D) A, B, $50 \mu \mathrm{m} ; \boldsymbol{C}, \boldsymbol{D}, 100 \mu \mathrm{m}$.

Table 1. GnRH neurons in CXCR4 mice

\begin{tabular}{rccll}
\hline & VN0 & Nasal septum & Brain & Total \\
\hline E12 & & & & \\
$+/+(n=3)$ & $163.7 \pm 28.4$ & $165.0 \pm 39.7$ & 0 & $328.7 \pm 11.9$ \\
$-I-(n=3)$ & $284.7 \pm 36.6$ & $11.3 \pm 2.3$ & 0 & $296.0 \pm 34.4$ \\
E13 & & & & \\
$+/+(n=3)$ & $44.0 \pm 9.5$ & $241.3 \pm 13.3$ & $270.3 \pm 31.7$ & $555.6 \pm 36.0$ \\
$-/-(n=2)$ & 204.0 & 107.5 & 7.0 & 318.5 \\
\hline
\end{tabular}

VNO, Vomeronasal organ; nasal septum; nasal compartment between the VNN and the cribriform plate; brain includes the olfactory bulb; total is for alternative sections through the nose and brain, and thus represents one-half of the total number of GnRH neurons per mouse.
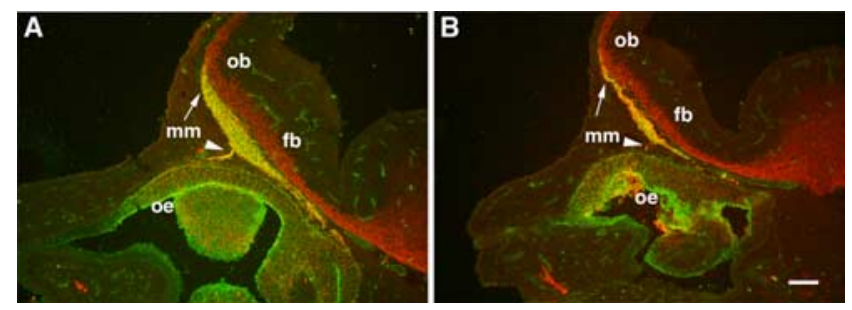

Figure 7. The MM is abnormal in CXCR4 ${ }^{-1-}$ mice. Double-label immunofluorescence analysis of sagittal sections through the nose and forebrain of E12 mice with the use of anti- $\beta$ IIItubulin (red) antibodies and FITC-conjugated LEA lectin (green) labels the MM (yellow). $\boldsymbol{A}$, In $\mathrm{CXCR}^{+/-}$mice double-labeled (yellow) MM cells and axons extend from the OE (arrowhead) to the rostral tip of the $O B$ (arrow), which has begun to protrude from the forebrain (fb). $B$, In a matched section through the nose and forebrain of a CXCR4 ${ }^{-1-}$ mouse, the MM is significantly smaller, containing many fewer double-labeled (yellow) cells and axons. In contrast, $\beta$ IIItubulin expression in the forebrain appears normal in CXCR4 ${ }^{-1-}$ mice. Scale bar, $100 \mu \mathrm{m}$.

tiated neurons by the time they migrate, whereas MM cells are mostly precursors of ensheathing glial cells that continue to divide as they migrate through the mesenchyme. In addition, most GnRH neurons retain CXCR4 expression during their migratory 


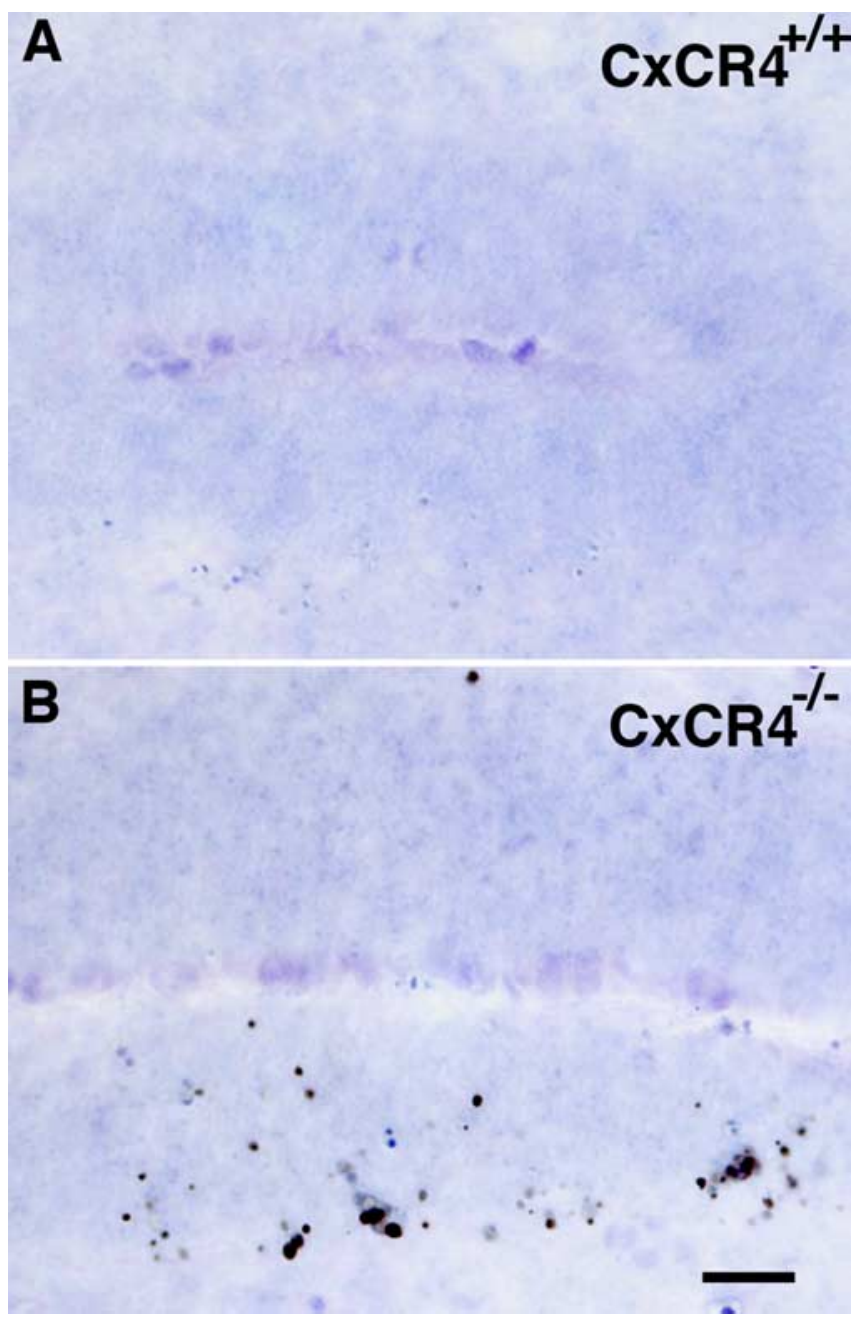

Figure 8. TUNEL analysis in sagittal sections of the VNO at E13 showing increased cell death in CXCR4 ${ }^{-I-}$ VNO neurons as compared with wild-type controls. $A$, In control animals at this age the basal level of apoptosis is low; no TUNEL-positive cells are detectable in this control image. $\boldsymbol{B}$, In CXCR4 ${ }^{-/-}$VNO there is a significant increase in TUNEL-positive cells, most of which are found in the ventral half of the VNO. Scale bar, $25 \mu \mathrm{m}$.

phase through the nasal mesenchyme at E13. In contrast, most MM cells lose CXCR4 expression by E11/E12, suggesting that factors in addition to SDF-1 regulate their migration. Interestingly, CXCR4 also is expressed by cells that do not migrate from the $\mathrm{OE}$ or $\mathrm{VNO}$, indicating that induction of cell movement is not the only outcome of CXCR4 signaling mechanisms. We also observed that CXCR4 was found rarely in potential GnRH neurons in the forebrain and was downregulated distinctly in GnRH neurons by E15 when many already had crossed into the forebrain. This suggests that GnRH neurons lose their responsiveness to SDF-1 to cross the cribriform plate and enter the forebrain.

Between E12 and E13 there is a significant decrease in the number of GnRH neurons in CXCR $4^{-1-}$ mice, and TUNEL analysis suggests that cell death is increased in the VNO of CXCR $4^{-1-}$ mice. It is unclear whether there is a similar increase in TUNEL-positive or caspase-3-positive cells in the MM, however. This may be attributable to a high basal level of cell death in the MM in wild-type mice at these embryonic ages, which may obscure increased cell death in the mutants. There are other possibilities for the observed decreases in GnRH and MM cells in CXCR4 mutants. It is possible that the production of $\mathrm{GnRH}$ or MM cells is decreased in CXCR4 $4^{-1-}$ mice; however, at early stages there is no difference in the number of GnRH neurons in the VNO between mutant mice and controls. Other possibilities are that CXCR4 signaling or continued migration toward the forebrain may be necessary for the maintenance of GnRH gene expression. In other mutant mice, such as netrin $1^{-1-}$ and ephrin3-5 $5^{-1-}$ mice, there also were reported losses in immunoreactive GnRH neuron numbers, but in neither case was the cause determined (Schwarting et al., 2004; Gamble et al., 2005). In the future it will be of considerable interest to determine whether SDF-1 provides trophic support for GnRH neurons or MM cells.

$\mathrm{KS}$ is a developmental disorder defined by $\mathrm{HH}$ and anosmia or, at least, extreme hyposmia. $\mathrm{HH}$ can be a result of the failed migration of GnRH neurons into the hypothalamus (SchwanzelFukuda et al., 1989). Anosmia is attributed to the failure of olfactory axons to make connections to the OB. Two genes, KAL and fibroblast growth factor 1 receptor $(K A L 2)$, have been implicated in a small percentage of cases of KS (Franco et al., 1991; Dode et al., 2003). Many patients with idiopathic $\mathrm{HH}$ (IHH) have a normal sense of smell, suggesting that migration of GnRH neurons and growth of the majority of olfactory axons into the $\mathrm{OB}$ can be dissociated. In an examination of 101 individuals with $\mathrm{IHH}$, it was found that 59 patients had true KS; that is, 42 had no anosmia (Oliveira et al., 2001). Only seven of the 59 cases of KS were associated with mutations in the coding sequence of the KAL gene. These findings suggest that the majority of autosomal cases of KS is caused by defects in autosomal genes (Oliveira et al., 2001). Furthermore, in the one case of fetal X-linked KS that was analyzed (Schwanzel-Fukuda et al., 1989), GnRH migration appeared to have occurred at least up to the region of the cribriform plate. In this regard, X-linked KS may not be a failure of migratory function but, rather, a block in the pathway between the nose and brain. It will be important to determine whether aberrant SDF-1/CXCR4 signaling as suggested by the current study may be involved in a subset of cases of $\mathrm{IHH}$.

Only a few molecules have been described as capable of modifying the rate at which $\mathrm{GnRH}$ neurons migrate (Tobet and Schwarting, 2006). These include GABA, ephrins A3 and A5, and polysialic acid-neural cell adhesion molecule (PSA-NCAM) (Tobet et al., 1996; Fueshko et al., 1998; Yoshida et al., 1999; Gamble et al., 2005), although each of these factors acts on only a subset of GnRH neurons. CNS chemokines have been implicated in attracting $\mathrm{GnRH}$ axons toward the median eminence, although the nature of these activities has not been defined further (Rogers et al., 1997; Gill and Tsai, 2006). We previously showed that netrin 1 acted as a chemoattractant for axon guides used by GnRH neurons to migrate into the hypothalamus, but it does not act directly on GnRH neurons (Schwarting et al., 2004). SDF-1/ CXCR4 is thus the first chemokine-receptor pair to be identified that is necessary for the migration of the majority of GnRH neurons from the VNO to the forebrain.

The effects of SDF-1 loss on the main olfactory system remain to be determined, although they appear to be less dramatic than the severe defects observed in GnRH neuron migration. Preliminary immunocytochemical studies that use anti-peripherin antibodies at E13 indicate that the olfactory nerve may be diminished in volume in mutant mice, although most olfactory axons establish contact with the developing $\mathrm{OB}$ in mutant mice (data not shown). Specific defects in olfactory axon guidance caused by abnormalities in MM formation will require an analysis of the targeting of individual odorant receptor-expressing neuron populations in CXCR4 $4^{-1-}$ mice. Results presented here, however, suggest that main olfactory connections remain at least partially intact in CXCR4 null mice. It will be interesting to determine 
whether some individuals with $\mathrm{IHH}$, that is, loss of $\mathrm{GnRH}$ function while retaining partial olfactory function, may have decreased or absent SDF-1 or CXCR4 activities.

\section{References}

Allen MP, Xu M, Zeng C, Tobet SA, Wierman ME (2000) Myocyte enhancer factors-2B and $-2 \mathrm{C}$ are required for adhesion-related kinase repression of neuronal gonadotropin-releasing hormone gene expression. J Biol Chem 275:39662-39670.

Bagri A, Gurney T, He X, Zou YR, Littman DR, Tessier-Lavigne M, Pleasure SJ (2002) The chemokine SDF1 regulates migration of dentate granule cells. Development 129:4249-4260.

Belmadani A, Tran PB, Ren D, Assimacopoulos S, Grove EA, Miller RJ (2005) The chemokine stromal cell-derived factor-1 regulates the migration of sensory neuron progenitors. J Neurosci 25:3995-4003.

Chalasani SH, Baribaud F, Coughlan CM, Sunshine MJ, Lee VM, Doms RW, Littman DR, Raper JA (2003) The chemokine stromal cell-derived factor-1 promotes the survival of embryonic retinal ganglion cells. J Neurosci 23:4601-4612.

De Carlos JA, Lopez-Mascaraque L, Valverde F (1995) The telencephalic vesicles are innervated by olfactory placode-derived cells: a possible mechanism to induce neocortical development. Neuroscience 68:1167-1178.

Dode C, Hardelin JP (2004) Kallmann syndrome: fibroblast growth factor signaling insufficiency? J Mol Med 82:725-734.

Dode C, Levilliers J, Dupont JM, De Paepe A, Le Du N, Souss-Yanicostas N, Coimbra RS, Delmaghani S, Compain-Nouaille S, Baveral F, Pecheux C, Le Tessier D, Cruaud C, Delpech M, Speleman F, Vermeulen S, Amalfitano A, Bachelot Y, Bouchard P, Cabrol S, et al. (2003) Loss-offunction mutations in FGFR1 cause autosomal dominant Kallman syndrome. Nat Genet 33:463-465.

Franco B, Guioli S, Pragliola A, Incerti B, Bardoni B, Tonlorenzi R, Carrozzo R, Maestrini E, Pieretti M, Taillon-Miller P (1991) A gene deleted in Kallmann's syndrome shares homology with neural cell adhesion and axonal path-finding molecules. Nature 353:529-536.

Fueshko SM, Key S, Wray S (1998) GABA inhibits migration of luteinizing hormone-releasing hormone neurons in embryonic olfactory explants. J Neurosci 18:2560-2569.

Gamble JA, Karunadasa DK, Pape JR, Skynner MJ, Todman MG, Bicknell RJ, Allen JP, Herbison AE (2005) Disruption of ephrin signaling associates with disordered axophilic migration of the gonadotropin-releasing hormone neurons. J Neurosci 25:3142-3150.

Gill JC, Tsai PS (2006) Expression of a dominant negative FGF receptor in developing GnRH1 neurons disrupts axon outgrowth and targeting to the median eminence. Biol Reprod 74:463-472.

Henion TR, Raitcheva D, Grosholz R, Biellmann F, Skarnes WC, Hennet T, Schwarting GA (2005) $\beta 1,3-N$-acetylglucosaminyl transferase 1 glycosylation is required for axon pathfinding by olfactory neurons. J Neurosci 25:1894-1903.

Jowett T (2001) Double in situ hybridization techniques in zebrafish. Methods 23:345-358.

Kafitz KW, Greer CA (1999) Olfactory ensheathing cells promote neurite extension from embryonic olfactory receptor cells in vitro. Glia 25:99-110.

Lu M, Grove EA, Miller RJ (2002) Abnormal development of the hippocampal dentate gyrus in mice lacking the CXCR4 chemokine receptor. Proc Natl Acad Sci USA 99:7090-7095.

Ma Q, Jones D, Borghesani PR, Segal RA, Nagasawa T, Kishimoto T, Bronson RT, Springer TA (1998) Impaired B-lymphopoiesis, myelopoiesis, and derailed cerebellar neuron migration in CXCR4- and SDF-1-deficient mice. Proc Natl Acad Sci USA 95:9448-9453.

Nagasawa T, Nakajima T, Tachibana K, Iizasa H, Bleul CC, Yoshie O, Mat- sushima K, Yoshida N, Springer TA, Kishimoto T (1996) Molecular cloning and characterization of a murine pre-B-cell growth-stimulating factor/stromal cell-derived factor 1 receptor, a murine homolog of the human immunodeficiency virus 1 entry coreceptor fusin. Proc Natl Acad Sci USA 93:14726-14729.

Oliveira LMB, Seminara SB, Beranova M, Hayes FJ, Valkenburgh SB, Schipani E, Costa EMF, Latronico AC, Crowley Jr WF, Vallejo M (2001) The importance of autosomal genes in Kallmann syndrome: genotypephenotype correlations and neuroendocrine characteristics. J Clin Endocrinol Metab 86:1532-1538.

Quinton R, Hasan W, Grant W, Thrasivoulou C, Quiney RE, Besser GM, Bouloux PM (1997) Gonadotropin-releasing hormone immunoreactivity in the nasal epithelia of adults with Kallmann's syndrome and isolated hypogonadotropic hypogonadism and in the early midtrimester human fetus. J Clin Endocrinol Metab 82:309-314.

Rogers MC, Silverman AJ, Gibson MJ (1997) Gonadotropin-releasing hormone axons target the median eminence: in vitro evidence for diffusible chemoattractive signals from the mediobasal hypothalamus. Endocrinology 138:3956-3966.

Roskams AJ, Cai X, Ronnett GV (1998) Expression of neuron-specific $\beta$-III tubulin during olfactory neurogenesis in the embryonic and adult rat. Neuroscience 83:191-200.

Schwanzel-Fukuda M, Pfaff DW (1989) Origin of luteinizing hormonereleasing hormone neurons. Nature 338:161-164.

Schwarting GA, Raitcheva D, Bless EP, Ackerman SL, Tobet S (2004) Netrin 1-mediated chemoattraction regulates the migratory pathway of LHRH neurons. Eur J Neurosci 19:11-20.

Stumm RK, Zhou C, Ara T, Lazarini F, Dubois-Dalcq M, Nagasawa T, Hollt $\mathrm{V}$, Schulz S (2003) CXCR4 regulates interneuron migration in the developing neocortex. J Neurosci 23:5123-5130.

Tissir F, Wang CE, Goffinet AM (2004) Expression of the chemokine receptor CXCR4 mRNA during mouse brain development. Brain Res Dev Brain Res 149:63-71.

Tobet SA, Schwarting GA (2006) Minireview: recent progress in gonadotropin-releasing hormone neuronal migration. Endocrinology 147:1159-1165.

Tobet SA, Chickering TW, King JC, Stopa EG, Kim K, Kuo-Leblank V, Schwarting GA (1996) Expression of $\gamma$-aminobutyric acid and gonadotropin-releasing hormone during neuronal migration through the olfactory system. Endocrinology 137:5415-5420.

Tran PB, Miller RJ (2003) Chemokine receptors in the brain: a developing story. J Comp Neurol 457:1-6.

Valverde F, Santacana M, Heredia M (1992) Formation of an olfactory glomerulus: morphological aspects of development and organization. Neuroscience 49:255-275.

Vilz TO, Moepps B, Engele J, Molly S, Littman DR, Schilling K (2005) The SDF-1/CXCR4 pathway and the development of the cerebellar system. Eur J Neurosci 22:1831-1839.

Wray S, Grant P, Gainer H (1989) Evidence that cells expressing luteinizing hormone-releasing hormone mRNA in the mouse are derived from progenitor cells in the olfactory placode. Proc Natl Acad Sci USA 86:8132-8136.

Yoshida K, Rutishauser U, Crandall JE, Schwarting GA (1999) Polysialic acid facilitates migration of luteinizing hormone-releasing hormone neurons on vomeronasal axons. J Neurosci 19:794-801.

Zhu Y, Yu T, Zhang XC, Nagasawa T, Wu JY, Rao Y (2002) Role of the chemokine SDF-1 as the meningeal attractant for embryonic cerebellar neurons. Nat Neurosci 5:719-720.

Zou YR, Kottmann AH, Kuroda M, Taniuchi I, Littman DR (1998) Function of the chemokine receptor CXCR4 in haematopoiesis and in cerebellar development. Nature 393:595-599. 